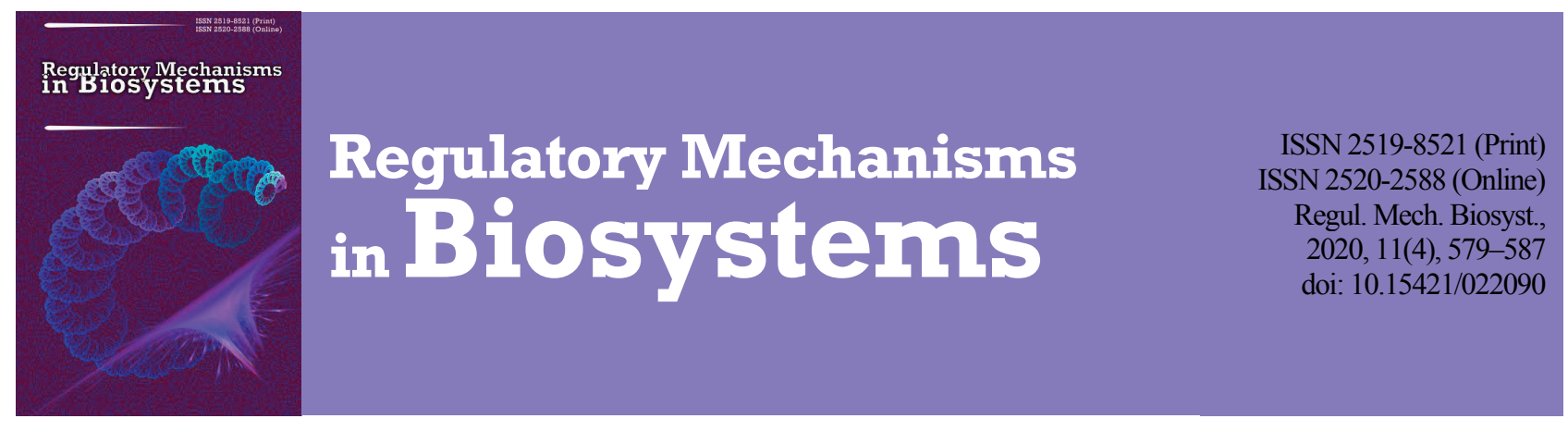

\title{
Effect of $\beta$-mannanase enzyme supplementation on the morphofunctional state of broiler chickens' immunocompetent organs
}

\author{
A. V. Oliyar, P. M. Skliarov, D. M. Masiuk, D. D. Bilyi, V. V. Logvinova, M. A. Lieshchova \\ Dnipro State Agrarian and Economic University, Dnipro, Ukraine
}

Article info
Received 15.10 .2020
Received in revised form
20.11.2020
Accepted 21.11 .2020

Dnipro State Agrarian and Economic University Serhii Efremov st., 25 , Dnipro, 49600, Ukraine. Tel.: +38-067-256-24-86 E-mail: lieshchova.m.o@dsau.dp.ua

\begin{abstract}
Oliyar, A. V., Skliarov, P. M., Masiuk, D. M., Bilyi, D. D., Logvinova, V. V., \& Lieshchova, M. A. (2020). Effect of B-mannanase enzyme supplementation on the morphofunctional state of broiler chickens' immunocompetent organs. Regulatory Mechanisms in Biosystems, 11(4), 579-587. doi:10.15421/022090
\end{abstract}

Identifying and eliminating factors that interfere with the nutrient absorption from feed is essential for successful poultry rearing. The nutritional value of feed mixtures used in the poultry industry can be increased by the use of enzyme supplements, in particular $\beta$ mannanase (Hemicell), which breaks down the anti-nutrients $\beta$-mannans that are present in significant quantities in soy products. For the study, two groups of 50 broiler chickens were formed. In the control group a standard feed mixture from cereals was used, particularly soybeans, and in the experimental group $0.05 \% \beta$-mannanase enzyme supplement (Hemicell) in addition to the compound feed was used. Production indicators were established (average daily gain, survival rate, feed costs). On the 15th, 25th and 42nd days of rearing, lymphatic organs (cloacal bursa and spleen) were collected from seven chickens of each group, followed by macro, microscopic and morphometric evaluation. It was found that the addition of an enzyme supplement promotes an increase in the production indicators of poultry rearing, reduces feed use, does not affect the macroscopic characteristics of the lymphatic organs. $\beta$-mannanase (Hemicell) contributes to the maintenance of an active morphofunctional state of the cloacal bursa and spleen during the entire period of poultry rearing. This was manifested by high indices of the absolute and relative organ masses, a moderate development degree of tissue components and cloacal bursa histological structures (number, shape and average length of lymphatic nodules, density of lymphocytes in the cortex and medulla) and spleen (number and diameter of lymphatic nodules and periarterioal lymphatic sheaths). In the control group, at all stages of rearing, the morphofunctional state of the bursa was found to be lower and signs of immunosuppression were revealed by the end of the rearing period (a sharp decline in the bursa absolute mass, organ mass index, a decrease in the average length of nodules, change in their shape, thinned cortical layer and delymphotisation). The morphofunctional state of the spleen of chickens from the control group remained high throughout the entire study period. So use of the $\beta$-mannanase enzyme supplement (Hemicell) while rearing broiler chickens not only increased the efficiency of their rearing but also contributed to maintaining a high morphological and functional state of the cloacal bursa.

Keywords: lymphatic tissue; lymphatic nodules; organ absolute mass; organ relative mass; cloacal bursa; spleen; production indicators.

\section{Introduction}

In agriculture, enzyme supplements are used to increase the digestibility of nutrients in the diet, which makes it possible to obtain additional products with the same feed costs. It's a well-known fact that feed accounts for $60-75 \%$ of the production cost and to increase the profitability of the industry, it is necessary to look for ways to improve the efficiency of its use. The scientific community is constantly looking for solutions to solve this problem. A number of drugs and feed additives are now widely used, among which an important place is given to enzyme supplements (Plesovskih, 1999; Azarfar 2013; Saleh et al., 2018).

Potentially dangerous factors that reduce the bioavailability of dietary nutrients include non-starch polysaccharides, which are high molecular weight complex carbohydrates found in the structure of plant cell walls (Annison \& Choct, 1991; Classen \& Bedford, 1991), and are present in significant amounts in soy products. These substances are contained in cell membranes in the form of glucomannans and galactomannans. $\beta$-Mannan is found in a variety of feeds and protein concentrates, it is widely used in animal feeding, and its negative effects are associated with reduced feed intake, reduced weight gain, and reduced feed to weight gain ratio (Furuse \& Mabayo, 1996). Soybean meal is known to contain $\beta$-mannan, which reduces the digestibility of the feed, and the addition of $\beta$-mannanase to the diet may increase its utilization (Patel \& McGinnis, 1985; Acamovic, 2001; Kuzmenko et al., 2020). $\beta$-Mannanase enzyme products (Hemi- cell) - are widely used to improve feeding efficiency and optimize economic costs, especially when it comes to poultry and pig diets based on soy and sunflower. The manufacturer says that these products are completely safe and can be used by animal nutritionists, their main active ingredient is the $\beta$-mannanase enzyme, which affects the anti-nutrients of $\beta$ mannan. $\beta$-Mannanase (Hemicell) is a natural product of microbial fermentation obtained from genetically unmodified strains of microorganisms (Rychen et al., 2017; Genedy et al., 2018; Saeed et al., 2019).

In scientific literature, reports on the effectiveness of $\beta$-mannanase are controversial. Several studies have shown the efficacy of Hemicell supplementation to improve average weight gain and feed conversion rates in broilers (Jackson et al., 2004; Wu et al., 2005; Zou et al., 2006). It was found that the introduction of guar flour into the diet (up to $10 \%$ ) caused a decrease in productivity and worsened the traits of broiler chicken carcasses, and the addition of the Hemicell enzyme to the same diet improved feed consumption, increased the feed conversion rate, did not affect body weight gain during fattening and did not change the carcass traits (Nabipour Afrouzi et al., 2016). However, Azarfar (2013) reported that Hemicell did not improve the performance and digestibility of crude protein and crude fat in the broilers' ileum. Ravindran et al. (1999) also did not find any positive effect of Hemicell on the performance of broiler chickens when they consume a diet based on cereals (corn, wheat).

Several studies have shown that Hemicell can improve animal immunity (Lee et al., 2005; Zangiabadi \& Torki 2010; Saleh et al., 2018). 
Some publications noted that the use of $\beta$-mannanase (Hemicell) had a positive effect on the state of the immune system organs. Thus, in an experiment with the addition of $\beta$-mannanase (Hemicell), it has increased the relative weight of immune organs, except for the relative weight of the thymus, in 3-week-old broilers, when $0.075 \%$ of an enzyme supplement was added to the main diet, and except for the relative weight of bursa of Fabricius in 6-week-old broilers, with the addition of $0.025 \% \beta$-mannanase (Hemicell). The use of this enzyme ( $0.05 \%$ of the main diet) also increased serum IgM and T-lymphocyte concentrations in 6-week-old broilers (Zou et al., 2006).

In birds, there are central and peripheral organs of the immune defense system. The central ones include the thymus, bone marrow and cloacal bursa - a lymphoepithelial organ, the involution of which, according to some reports, develops 35 days after hatching (Tarek et al., 2011) or laterafter 160 or even 220 days according to other authors (Zharova, 2008; Khomych et al., 2015). Such a discrepancy in the timing of the involution onset may be associated with the active bird vaccination, because this organ is directly responsible for the formation of humoral immunity, and all processes occurring in it are directly related to immunomorphology. In this regard, it is important to assess the morphological and functional state of the organs that are directly responsible for the immunological reactivity of the bird's body (Krasnikov \& Keleberda, 1999; Gromov 2010; Zhyla et al., 2016). Such an assessment of the state of immunocompetent organs in a practical aspect is based on the qualitative and quantitative indicators of their tissue, cellular and molecular components, and antibodies, and it is the basis for monitoring the effectiveness and safety of feed additives, immunomodulators, drugs, and vaccines used in veterinary medicine and animal husbandry (Acamovic, 2001; Bäck, 2009; Stehnii, 2013; Romanovych et al., 2019).

Therefore, the aim of the work was to establish the morphofunctional state of the broiler chickens' immunocompetent organs when using the enzyme supplement $\beta$-mannanase (Hemicell) in their diet.

\section{Material and methods}

The study was reviewed and approved by the Local Ethics Committee of the Dnipro State Agrarian and Economic University (Dnipro, Ukraine). The research was conducted at the vivarium of Dnipro State Agrarian and Economic University, Dnipro, Ukraine. For the experiment, two groups of broiler chickens were formed, 50 birds each at the age of one day. For the first group (control), a standard feed mixture was used in the form of a compound feed balanced in nutrients, vitamins and trace minerals. The diet was based on cereals (wheat, corn, sunflower meal, extruded soybean, soybean meal, bran, protein-vitamin complex). In the second group (experimental), in addition to the compound feed, $0.05 \%$ enzyme formulation $\beta$-mannanase Hemicell (manufactured by ChemJen, USA) (Rychen et al., 2017) was used. It is a dark brown powder, thermostable, with an enzymatic activity recovery rate of $90-95 \%$.

The guaranteed activity of $\beta$-mannanase is 160 million IU/kg. Composition: $1 \mathrm{~kg}$ contains the $\beta$-mannanase active substance (Bacillus lentus $)-160 \times 10^{6}$ units. The experiment lasted 42 days. Materials for research were central (cloacal bursa) and peripheral (spleen) immunocompetent organs, that were collected from broiler chickens of the control and experimental groups on the 15th, 25th, and 42nd days of growing. Histological examinations were carried out in the Pathomorphology and Immunohistochemistry Department of the Scientific Research Center of Biosafety and Environmental Control Agro-Industrial Complex (Biosafety-Center) of the Dnipro State Agrarian and Economic University, Dnipro, Ukraine.

To establish production indicators, a regular weekly review and weighing were carried out, and the average daily gain, survival rate, and feed costs were calculated. On the 15th, 25th, and 42nd days, 7 chickens were selected from the experimental and control groups. The diagnostic slaughter of poultry was carried out by decapitation under chloroform anaesthesia in accordance with the recommendations of the European Convention for the Protection of Vertebrate Animals used for Experimental and other Scientific Purposes, in compliance with the requirements of the International Epizootic Bureau and the existing rules of bioethics. A complete post-mortem examination was performed, the cloacal bursa and spleen were taken, their absolute weights were determined (Horalskiy et al., 2019). The organ mass index was determined by the formula:

$$
\mathrm{MI}=\mathrm{m}: \mathrm{M} \times 1000 \text {, }
$$

where $\mathrm{MI}$ is the mass index, $\mathrm{m}$ is the mass of the organ, $\mathrm{M}$ is the bodyweight of the animal, 1000 is a coefficient.

The organs were examined for possible pathological changes (e.g. inflammation, dystrophy, necrosis, hyperemia), they were fixed in a $10 \%$ solution of neutral formalin, embedded in paraffin, and thin histological sections $(5-7 \mu \mathrm{m})$ were made, which were stained with hematoxylin and eosin according to standard techniques (Horalskiy et al., 2019). The histological preparations were examined using a Leica DM1000 light microscope (eyepiece $\times 4$, objectives $\times 10 / 0.25, \times 40 / 0.65)$ integrated with a personal computer.

To assess the morphofunctional state of the organs, the degree of development and ratio of tissue components in the cloacal bursa were identified, the average length and shape of the lymphatic nodules, the thickness of their cortex, the configuration and tightness of the nodules were determined, the development of the inter-nodular connective tissue, the nature of the cytoarchitectonics of the cortex and medulla, and the density of cell distribution were taken into account, structural features of the stroma of nodules and their cortico-medullary layer (Avtandilov, 1990). In the spleen, the degree of development of the stroma (capsule and trabeculae) and parenchyma (white and red pulp) was determined, also the development of the white pulp (lymphatic nodules, periarterioal lymphatic sheaths) was assessed. In histological sections of the cloacal bursa, the length of the five largest lymphoid nodules was measured, in the spleen the diameter of the lymphoid nodules and periarterial lymphoid sheaths, the thickness of the cortex of the nodules was determined by the number of cell layers. The research results were processed statistically using oneway analysis of variance (ANOVA). In the tables, data are presented as mean values $(\mathrm{X})$ and their standard deviations $(\mathrm{SD})$.

\section{Results}

Under the same initial conditions, namely the weight of birds at the beginning of the experiment and the duration of rearing (42 days), the performance indicators of the experimental group were higher than the control group (Table 1). In the experimental group of broiler chickens, the survival rate, average weight of one bird at slaughter, average daily gain, meat yield in live weight slightly exceeded control. At the same time, the amount of feed per $1 \mathrm{~kg}$ of live weight was lower in broiler chickens on a regular diet. During the entire rearing period, the average weight of chickens in the experimental group was higher than in the control one (Table 2). On the 42nd day of bird rearing of both groups they corresponded by development to the normative data, however, the average weight indices in the chickens of the experimental group were $2782 \pm 183 \mathrm{~g}$, and in the control group below $2532 \pm 111 \mathrm{~g}$, which is of great importance for profitability in poultry farming.

\section{Table 1}

Production indicators of rearing broiler chickens using $\beta$-mannanase $(\mathrm{x} \pm \mathrm{SD}, \mathrm{n}=50)$

\begin{tabular}{lcc}
\hline \multicolumn{1}{c}{ Group } & Experimental & Control \\
\hline $\begin{array}{l}\text { Broiler weight at the beginning } \\
\text { of the experiment, g }\end{array}$ & $42.9 \pm 0.47$ & $43.0 \pm 0.59$ \\
Age of slaughter, day & 42 & 42 \\
Survival rate, \% & 97.4 & 9.7 \\
Average daily weight gain, g & $66.4 \pm 2.39$ & $65.0 \pm 1.96^{*}$ \\
Average bird mass at slaughter, $\mathrm{kg}$ & $2.77 \pm 0.10$ & $2.51 \pm 0.21^{*}$ \\
Meat yield in live weight, kg & $61.7 \pm 10.2$ & $55.8 \pm 6.3$ \\
Amount of feed per 1 kg of live weight, $\mathrm{kg}$ & $1.60 \pm 0.13$ & $1.59 \pm 0.12$ \\
\hline
\end{tabular}

Note: differences between the experimental and the control group are significant at the level * $-\mathrm{P}<0.05 ; * *-\mathrm{P}<0.01 ; * * *-\mathrm{P}<0.001$.

In the control and experimental groups of 15-day-old chickens, their cloacal bursa had a rounded shape, light pink colour, and had an elastic consistency. The incision shows pronounced folding, pale pink colour, a small amount of mucus between the mucous membrane folds. The spleen was smaller, rounded, dark red to light brown in colour. The size and general appearance of the chicken's organs of both groups did not practi- 
cally differ. During rearing on the 25th and 42nd days, the macroscopic indicators of the examined organs did not differ significantly between the two groups. The organs had the correct anatomical configuration and were of the appropriate shape and size.

The absolute weight of the cloacal bursa of 15-day-old chickens in the control group was 1.17 grams, and in the chickens of the experimental group this indicator was almost the same -1.11 grams (Table 2). By the age of 25-days, the chickens' cloacal bursa weight in both groups had increased, in the experimental group up to 2.04 grams, in the control group only up to $1.80 \pm 0.16$ grams. By the 42 nd day, cloacal bursa absolute mass in the experimental group had doubled and amounted to $4.09 \pm 0.30$ grams, in the control group it had increased by $22 \%$. During the experiment, the absolute mass of the cloacal bursa in chickens from the experimental group was significantly higher than in the control group.

In our experiment, the bursa mass index of the chickens in the control group was 2.33, and in the experimental group, it was only 2.09. By the age of 25-days, the bursa mass index in both groups had sharply decreased and did not differ significantly. By the time of birds' slaughter, this indicator in the control group had decreased to 0.45 , and in the experimental group, on the contrary, increased to 1.47 .

In the chickens of the control group on the 15th day, the average absolute weight of the spleen was $0.58 \pm 0.10$ grams, and in the experimental group $-0.67 \pm 0.13$ (Table 2). By the age of 25 days, the absolute weight of the spleen in chickens of both groups had moderately increased, and by 42 days of age, it had increased sharply. This process was more intense in the control group. So at the time of slaughter, the spleen absolute weight of control group chickens was significantly higher than the weight of the organ in the experimental group. The spleen mass index in 15-day-old chickens did not differ significantly between the groups, in the control group it was 1.15, and in the experimental one-1.25. During the experiment, this indicator changed synchronously in both groups, sharply decreased by the age of 25 days, and increased by the slaughter time. In the control group of broiler chickens, by the 25th day of the experiment, the spleen mass index had decreased to 0.83 , and in the experimental group - to 0.66 . In 42-day-old chickens, the spleen mass index in the control group was 1.11 , and in the experimental group, it was only 0.80 (Table 2 ).

Microscopic examination of 15-day-old chickens' cloacal bursa showed that the histological structure of the organs of birds in both groups corresponded to physiological parameters. The wall of the cloacal bursa was formed by serous, muscular and mucous membranes. The serous membrane was characterized by the usual structure - loose connective tissue and mesothelium, the muscular membrane was formed by smooth muscle tissue, myocytes were forming the inner circular and outer longitudinal layers. The mucous membrane of the cloacal bursa was formed with folds directed along the organ. On the surface of the folds, a singlelayer columnar epithelium was represented by prismatic epithelial cells and goblet cells that synthesize and secrete mucus. At the base of the mucous membrane folds were bundles of collagen fibers that formed membranes around the lymphatic nodules. The lamina propria was a wellvascularized loose connective tissue. Lymphatic nodules had a round, elongated-oval, polygonal shape (Fig. 1).

Table 2

Macromorphometric parameters of the immune organs of chickens under the effect of $\beta$-mannanase, $(x \pm S D, n=7)$

\begin{tabular}{|c|c|c|c|c|c|c|}
\hline Group & & Experimental & & & Control & \\
\hline Age, day & 15 & 25 & 42 & 15 & 25 & 42 \\
\hline Chickens' weight, $g$ & $533 \pm 8$ & $1530 \pm 41$ & $2783 \pm 183$ & $505 \pm 13^{* * *}$ & $1332 \pm 50 * * *$ & $2532 \pm 111^{* *}$ \\
\hline Cloacal bursa absolute mass, $\mathrm{g}$ & $1.11 \pm 0.16$ & $2.04 \pm 0.16$ & $4.09 \pm 0,30$ & $1.17 \pm 0.19$ & $1.80 \pm 0.16^{*}$ & $2.31 \pm 0.41 * * *$ \\
\hline Cloacal bursa mass index & $2.09 \pm 0.29$ & $1.33 \pm 0.12$ & $1.47 \pm 0.15$ & $2.33 \pm 0.40$ & $1.35 \pm 0.11$ & $0.45 \pm 0.05^{* * *}$ \\
\hline Spleen absolute weight, $\mathrm{g}$ & $0.67 \pm 0.13$ & $1.02 \pm 0.12$ & $2.20 \pm 0.18$ & $0.58 \pm 0.10$ & $1.11 \pm 0.17$ & $2.81 \pm 0.27^{* * *}$ \\
\hline Spleen mass index & $1.25 \pm 0.24$ & $0.66 \pm 0.09$ & $0.80 \pm 0.08$ & $1.15 \pm 0.22$ & $0.83 \pm 0.15^{*}$ & $1.11 \pm 0.10^{* * *}$ \\
\hline
\end{tabular}

Note: differences between the experimental and the control group are significant at the level ${ }^{*}-\mathrm{P}<0.05,{ }^{*}-\mathrm{P}<0.01,{ }^{* * *}-\mathrm{P}<0.001$.
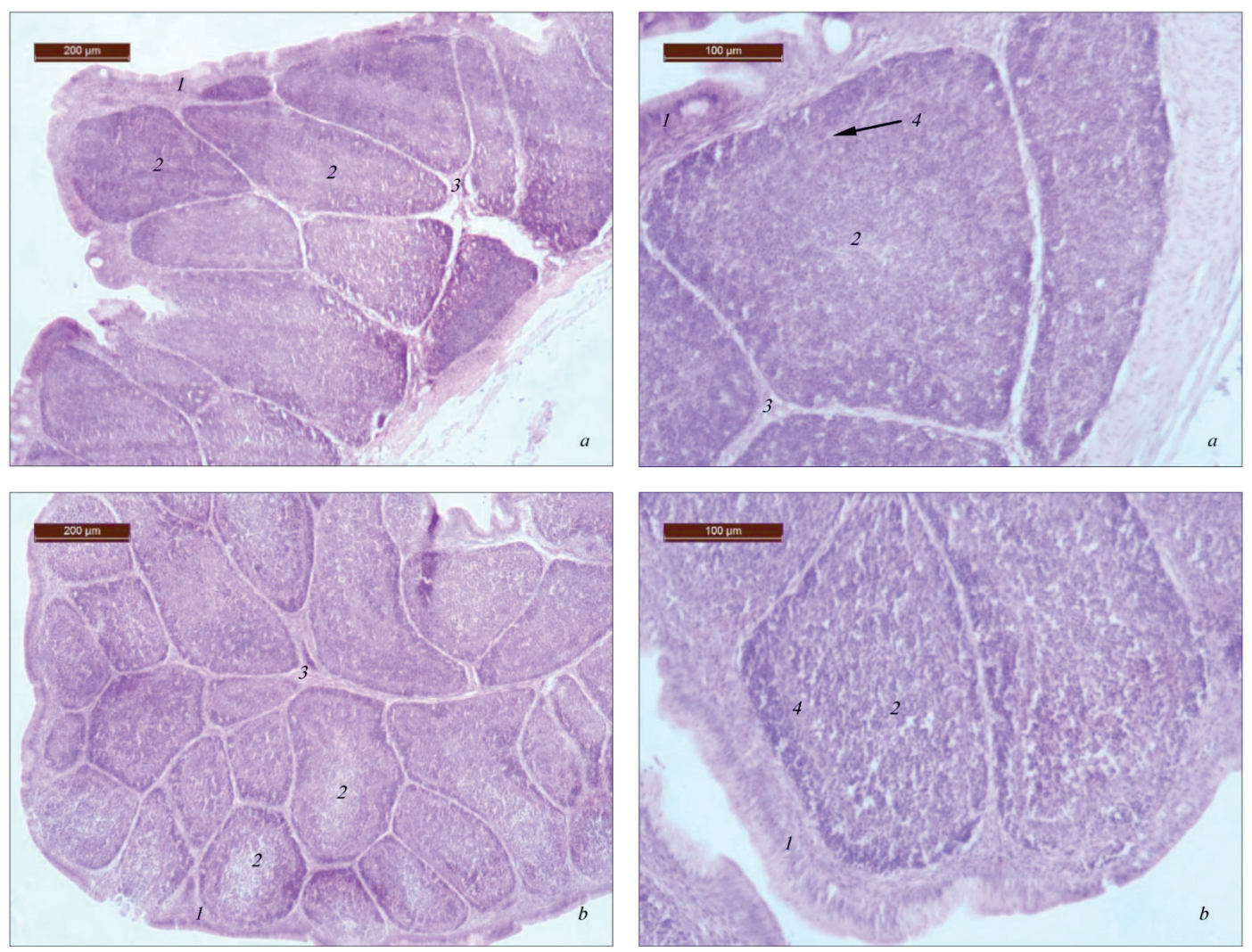

Fig. 1. Histological preparation of the cloacal bursa of 15-day-old chickens from the control $(a)$ and research $(b)$ groups:

1-epithelium; 2-lymphatic nodules; 3 -internodular connective tissue; 4-cortico-medullary junction; hematoxylin and eosin 
In the cloacal bag of 15-day-old chickens of both groups, the organ condition was satisfactory. The folds of the mucous membrane were evenly covered with epithelium. Lymphatic nodules were round, roundedoval, and polygonal, densely and evenly filled with lymphocytes. The border between the cortex and medulla was erased, the cortico-medullary barrier was hardly noticeable. The morphometric indices of lymphatic nodules of the cloacal bursa of broiler chickens from the control group were lower than those of the experimental chickens. The average length of cloacal bursa lymphatic nodules in 15-day-old chickens from the control group was only $368 \pm 30 \mu \mathrm{m}$, while in the experimental group it was significantly more than $446 \pm 23 \mu \mathrm{m}(\mathrm{P}<0.001)$. The average number of cell rows in the cortex of the cloacal bursa lymphoid nodules in chickens of the control group was $8.97 \pm 0.34$, and in the experimental group $9.76 \pm 0.26$ (Table 3).

On the histological preparation of the bursa of 25-day-old chickens, the difference between the groups was more pronounced. Microscopically, a low morphofunctional state of the cloacal bursa in the control group was established. Despite the fact that the folds remained high, the amount of inter-nodular connective tissue was increased, the nodules were not tight to each other. They were predominantly polygonal in shape, rather densely filled with lymphocytes. The cortex and medulla of the nodules, a noticeable cortico-medullary layer were well separated. In the medulla of most nodules, a decrease of lymphocyte density was noted, due to which the border between the cortex and medulla was clearly visible (Fig. 2a). In the experimental group chickens, the lymphatic nodules fitted tightly one to one, had a predominantly oval-elongated shape. The density of their filling with lymphocytes was practically the same as in the previous age group. The density of lymphocytes in the cortex and in the medulla was practically the same (Fig. 2b).

In 25-day-old chickens of the control group, the average length of lymphatic nodules in comparison with the previous age almost doubled (up to $423 \pm 15 \mu \mathrm{m}$ ), but was significantly lower than the corresponding parameter of chickens in the experimental group (Table 3). The same tendency was characterized by the width of the nodules cortex. In birds of the control group, the number of cell rows in the cortex of the nodules did not not exceed $7.89 \pm 0.21$, which was the lowest indicator for the entire period of research. In the experimental group of chickens, the cloacal bursa lymphatic nodules were the largest (average length $482 \mu \mathrm{m}$ ), and the width of their cortex reached 10.63 cell rows, which was significantly greater than the indicator of chickens in the control group.

\section{Table 3}

Micromorphometric parameters of the chickens' immune organs under the effect of $\beta$-mannanase $(x \pm S D, n=7)$

\begin{tabular}{|c|c|c|c|c|c|c|}
\hline Group & \multicolumn{3}{|c|}{ Experimental } & \multicolumn{3}{|c|}{ Control } \\
\hline Research period, days & 15 & 25 & 42 & 15 & 25 & 42 \\
\hline The average length of cloacal bursa lymphatic nodules, $\mu \mathrm{m}$ & $446 \pm 23$ & $482 \pm 16$ & $325 \pm 21$ & $368 \pm 30 * * *$ & $423 \pm 15^{* * *}$ & $287 \pm 17^{*}$ \\
\hline The width of the cortex of the cloacal bursa nodules (rows of cells) & $9.76 \pm 0.26$ & $10.63 \pm 0.49$ & $12.65 \pm 0.51$ & $8.97 \pm 0.34 * *$ & $7.89 \pm 0.21 * * *$ & $11.22 \pm 1.22 *$ \\
\hline The width of the spleen periarterioal lymphatic sheath, $\mu \mathrm{m}$ & $68.9 \pm 2.2$ & $80.17 \pm 2.46$ & $66.35 \pm 6.17$ & $82.12 \pm 4.84^{* * *}$ & $94.62 \pm 4.53 * * *$ & $83.70 \pm 2.93 *$ \\
\hline The average diameter of the spleen lymphatic nodule, $\mu \mathrm{m}$ & $92.7 \pm 11.8$ & $141.12 \pm 9.42$ & $\begin{array}{c}137.55 \pm \\
21.73\end{array}$ & $154.63 \pm 24.10^{* * *}$ & $171.31 \pm 12.09 * * *$ & $140.11 \pm 24.32$ \\
\hline
\end{tabular}

Note: differences between the experimental and the control group are significant at the level $*_{-} \mathrm{P}<0.05, * *-\mathrm{P}<0.01, * * *-\mathrm{P}<0.001$.
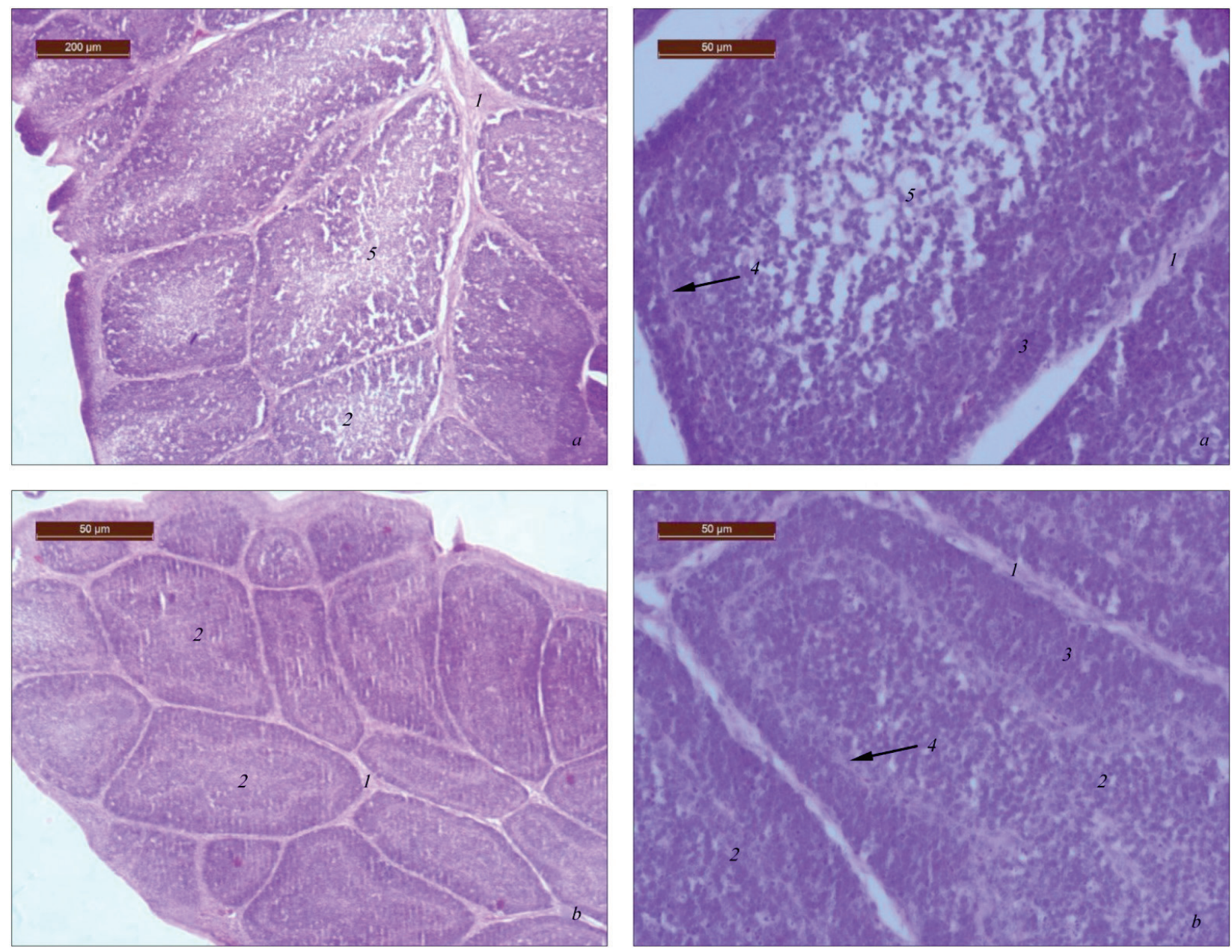

Fig. 2. Histological preparation of the cloacal bursa of 25-day-old chickens from the control $(a)$ and research $(b)$ groups:

1 -internodular connective tissue; 2-lymphatic nodules; 3 -cortex; 4-cortico-medullary junction; 5 -decrease of lymphocyte density in the medulla; hematoxylin and eosin 
In 42-day-old broiler chickens of the control group, a low morphofunctional state of the organ was found. At the same time, in control birds, histologically, the cloacal bursa had insignificantly expressed signs of involution. The birds of the control group exhibited a significant amount of inter-nodular connective tissue, where bundles of collagen fibers predominated. The shape of nodules varied from oval to irregular polygonal; their average length did not exceed $287 \pm 17 \mu \mathrm{m}$. The filling of nodules with lymphocytes was uneven. There was a small number of lymphocytes in the cortex (11.22 \pm 1.22 rows of cells); their loose distribution was noted, and delymphatisation in the medulla. The border between the cortex and medulla was erased and uneven (Fig. 3a).

In the birds of the experimental group, on the 42nd day of rearing, a rather high morphological and functional state of the organ was noted. Lymphatic nodules were oval, rhomboid, less often polygonal, with a moderate amount of loose connective tissue between them. The nodules themselves were densely filled with lymphocytes, their average length had decreased in comparison with the previous age, but was significantly higher than the corresponding parameter of the chickens in the control group (Table 3). The border between the cortex and medulla was well defined. The cortical substance was formed by almost 12 layers of lymphocytes, and in the medulla, there was a moderate rarefaction (Fig. 3b).

It was found that on the 15th day of rearing the spleen of the experimental group chickens was a formed organ with pronounced parenchyma and stroma, represented by a connective tissue capsule and thin trabeculae. The parenchyma was divided into red and white pulp, which was represented by formed lymphatic nodules and periarterioal lymphatic sheaths (Fig. 4a). In the spleen of 15-day-old chickens from the control group, more pronounced and numerous periarterioal lymphoid sheaths were observed, their width was $82.1 \pm 4.8 \mu \mathrm{m}$, and the average diameter of lymphatic nodules was $154.6 \pm 24.1 \mu \mathrm{m}$ (Table 3 ). In the experimental group of chickens, on the 15th day of rearing, the spleen's morphofunctional state was lower, expressed in the indistinct division of the pulp into red and white, an extremely insignificant number of lymphatic nodules, the diameter of which did not exceed $92.7 \pm 11.8 \mu \mathrm{m}$, they were single on the general section of the organ (Fig. 4b). Lymphatic nodules were poorly formed, with indistinct borders. There were numerous periarterial lymphatic sheaths, however, they were small, and their diameter did not exceed $68.9 \pm$ $2.2 \mu \mathrm{m}$.

On the 25th day of rearing, a high morphometric potential of the spleen was found in the control group chickens. It had a clear division of the pulp into red and white, there was a significant number of lymphatic nodules, round in shape, with a clear border from the red pulp. Their diameter was $171.3 \pm 12.1 \mu \mathrm{m}$, which was the highest value during the entire research period (Table 3). Periarterial lymphatic sheaths were numerous and wide, filled up with lymphocytes; their diameter also reached a maximum size of $94.6 \pm 4.5 \mu \mathrm{m}$ (Fig. 5).

In the chickens of the experimental group, on the 25th day of rearing, in the spleen, the activation of the organ immunological function was noted. This was manifested by an increase in the number and size of lymphatic nodules, there were 3-4 of them on the general section of the organ, the average diameter was $141.1 \pm 9.4 \mu \mathrm{m}$, which was significantly higher than in the previous age, but significantly less than in the control. Periarterial lymphatic sheaths were well-formed; their average diameter was also greater than the previous age of the bird $(80.5 \pm 2.5 \mu \mathrm{m})$.

By the end of poultry rearing in both groups, a decrease in the morphometric potential of the spleen white pulp structures was noted. The red pulp was not well enough separated from the white, the lymphatic nodules were few (3-4) on the general section of the organ, had clear borders, a rounded shape. In the control group of birds, the average diameter of lymphatic nodules was $140.1 \pm 24.3 \mu \mathrm{m}$, and the diameter of periarterial lymphatic sheaths was $83.7 \pm 2.9 \mu \mathrm{m}$. They were single, wide enough, densely filled with cellular elements (Fig. 6a).
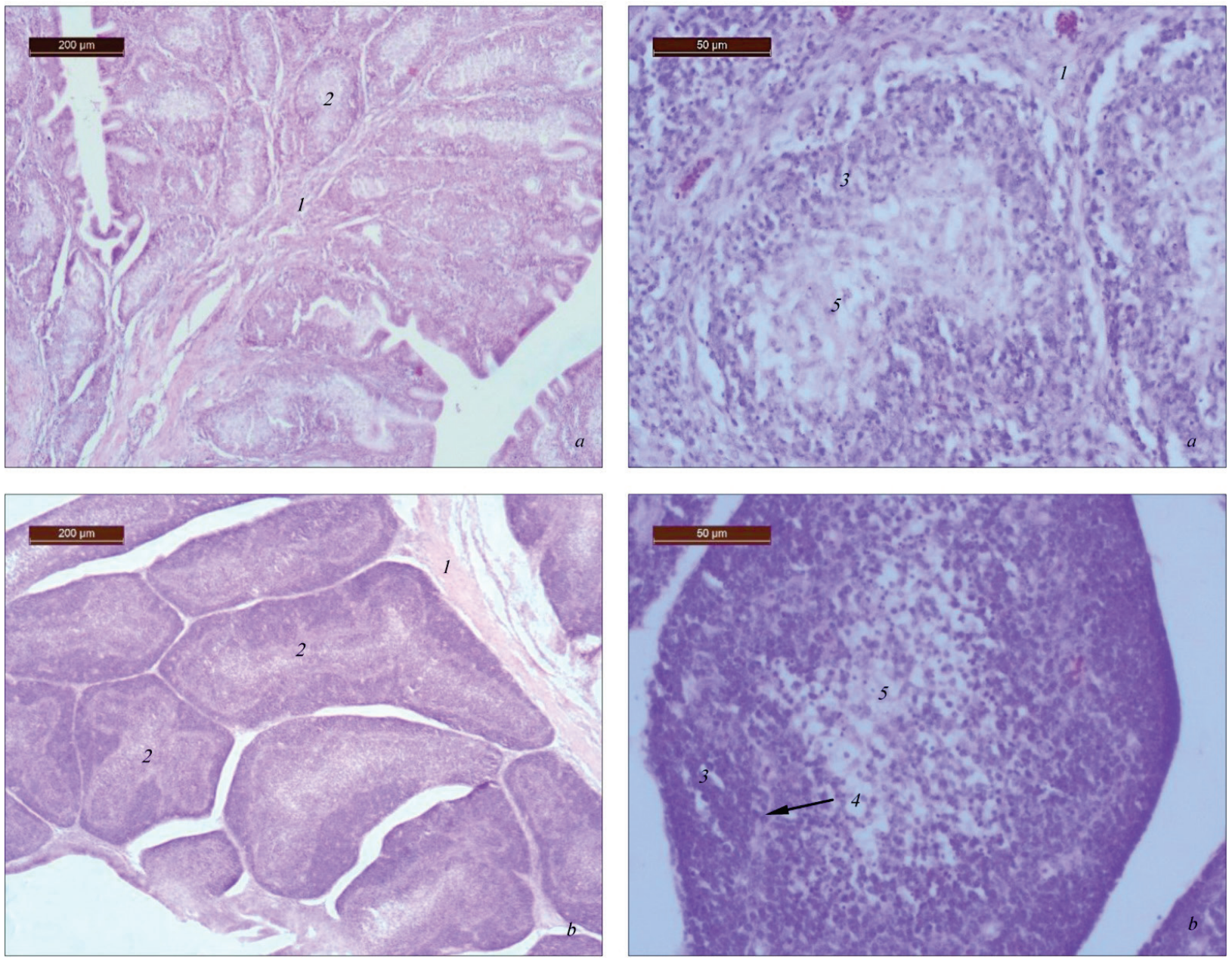

Fig. 3. Histological preparation of the cloacal bursa of 42-day-old chickens from the control $(a)$ and research $(b)$ groups:

1 -internodular connective tissue; 2 -lymphatic nodules; 3 -cortex; 4 - cortico-medullary junction; 5 -decrease of lymphocyte density in the medulla; hematoxylin and eosin 

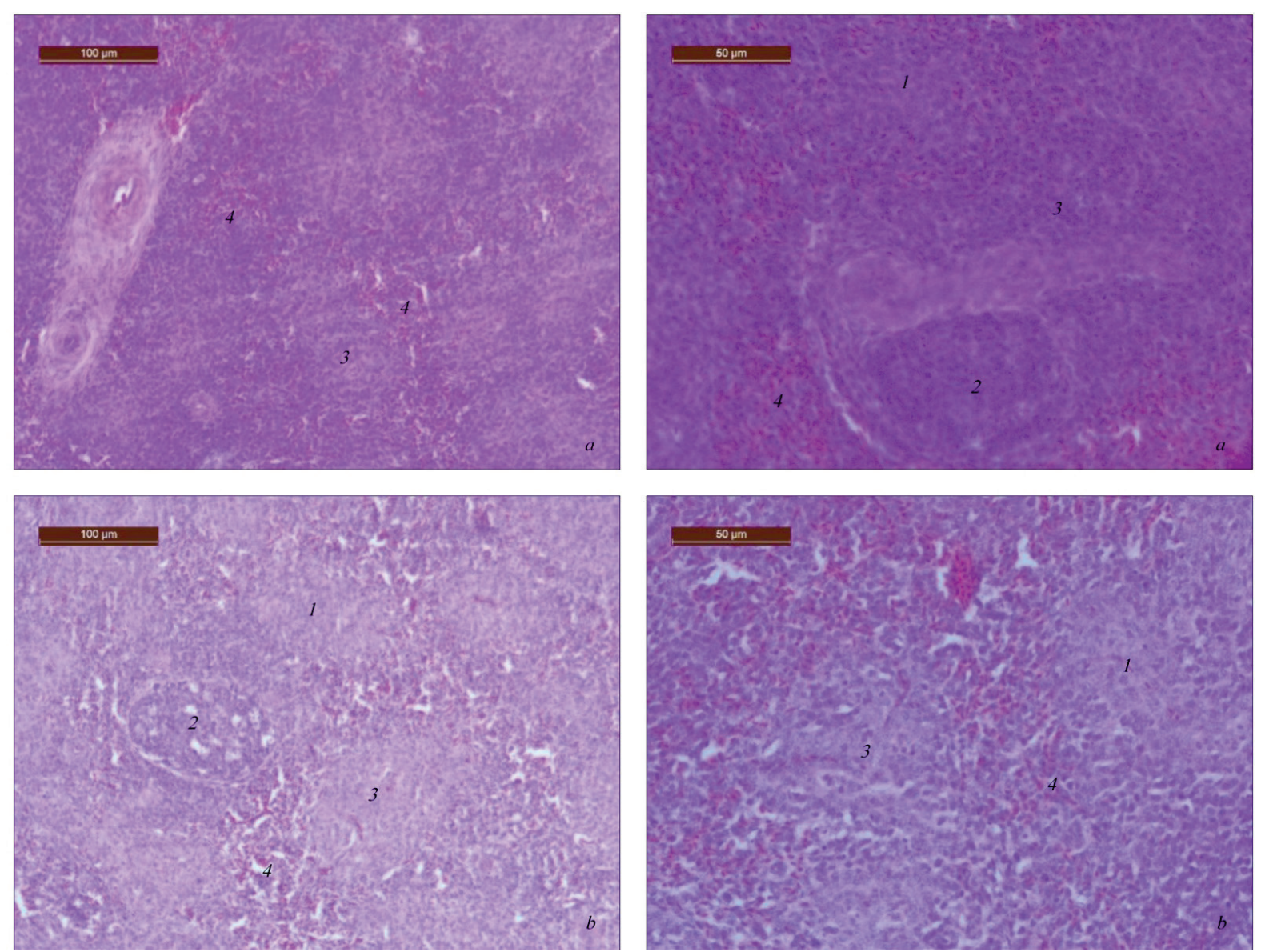

Fig. 4. Spleen of 15-day-old chickens of the control $(a)$ and research $(b)$ groups:

1 -white pulp; 2 -lymphatic nodule; 3 - periarterioal lymphatic sheath; 4 -red pulp; hematoxylin and eosin
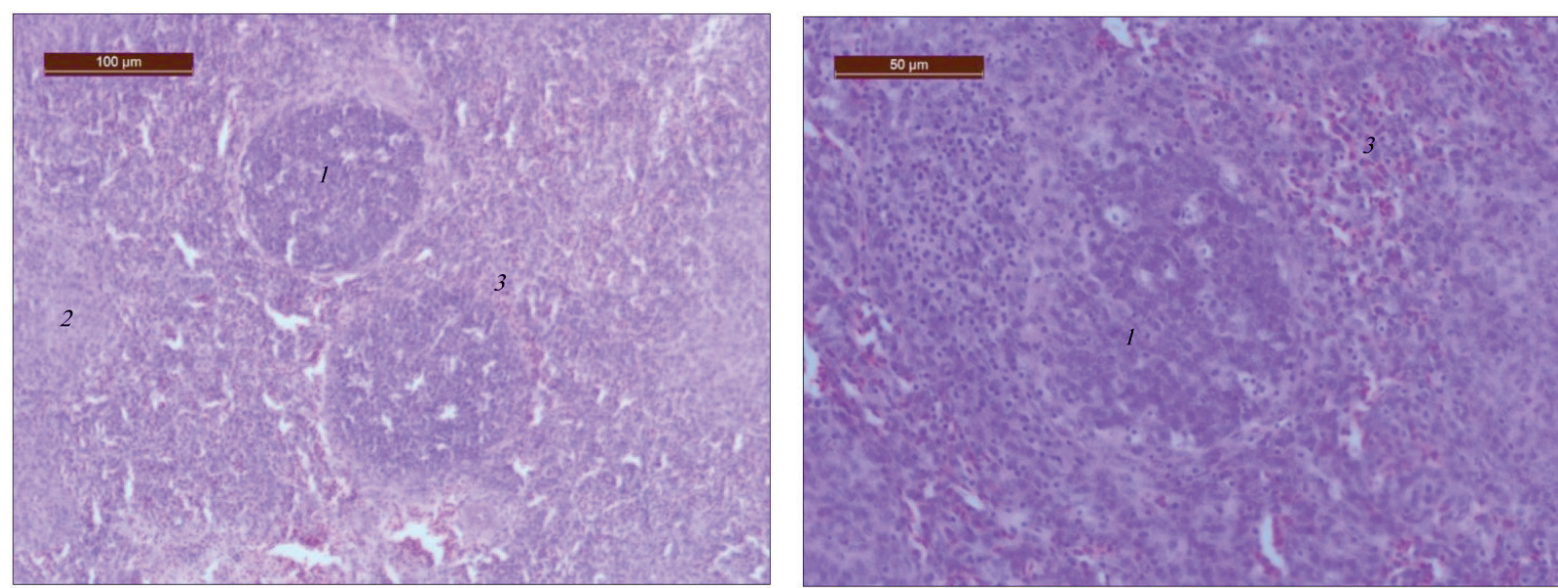

Fig. 5. Spleen of 25-day-old chickens of the control group: 1 -lymphatic nodule; 2 - periarterioal lymphatic sheath; 3 -red pulp; hematoxylin and eosin

In the spleen of the experimental group chicken broilers, the morphometric parameters of the white pulp components were slightly lower than those of the control group. Thus, the diameter of the lymphatic nodules in this group was $137.6 \pm 21.7 \mu \mathrm{m}$, which was lower as compared to the 25-day age and the parameter of the peers in the control group (Fig. 6b). The diameter of the periarterial lymphatic sheaths did not exceed $66.4 \pm 6.2 \mu \mathrm{m}$, which was the lowest indicator for the entire study period and was significantly lower than that of the control group birds.

\section{Discussion}

Animal diets with soybean meal containing $\beta$-mannan significantly reduce feed intake, while the addition of $\beta$-mannanase improves feed absorption. Studies have shown that the addition of $\beta$-mannanase (Hemicell) to the diet with soybean meal improved the average daily weight gain and feed conversion of broilers. Interestingly, no significant differences were found between broiler groups that were given different doses of the enzyme preparation $(0.025 \%, 0.050 \%, 0.075 \%)$ (Zou et al., 2006). These results are consistent with those of Jackson et al. (2004), who also reported high gains in weight and conversion when Hemicell was added to the diet. Inclusion in the diet of $\beta$-mannanase at a dose of 80 million U/tonne improved the weight gain in broilers while increasing the dose to 110 million U/tonne did not lead to a significant additional effect.

By a comprehensive study of the effect of the enzyme supplementation $\beta$-mannanase (Hemicell) in our experiment, we found that the production indicators of the group of broilers to which the supplement was added to the diet, survival, average weight of one bird at slaughter, average daily gain, meat yield in live weight were higher than in the control group. The amount of feed per $1 \mathrm{~kg}$ of live weight was lower in broiler chickens on a regular diet. 

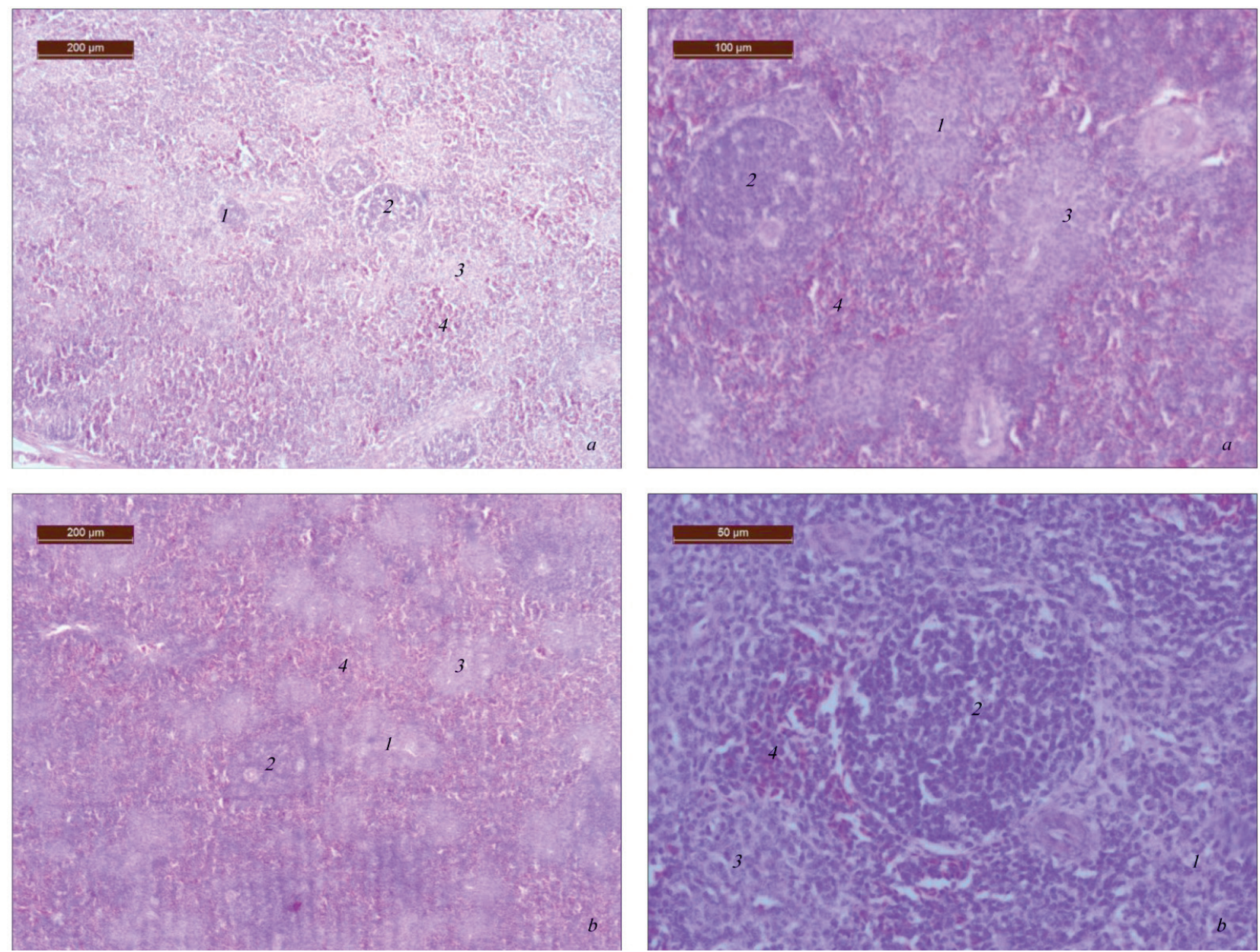

Fig. 6. Spleen of 42-day-old chickens of the control $(a)$ and research $(b)$ groups:

1 -white pulp; 2 -lymphatic nodule; 3 - periarterioal lymphatic sheath; 4-red pulp; hematoxylin and eosin

At the same time, Azarfar (2013) in an experiment on broiler chickens with the addition of 0.5 and $1.0 \mathrm{~g} / \mathrm{kg}$ of the Hemicell enzyme supplement to the diet did not reveal its significant effect on production performance. Also, in a study on broiler chickens of the Ross 308 cross, it was found that the addition of this dietary supplement to the diet did not show a significant effect on the parameters and their growth rate when evaluated using the Gompertz growth model (López, 2008; Azarfar 2013).

Lee et al. (2005) reported that Hemicell significantly reduced the feed to weight gain ratio in guar flour-supplemented diets to the positive and negative control levels. The experiment showed that the decrease in the feed to weight gain ratio directly depends on the enzyme dose. When adding $0.5 \%, 1.0 \%, 1.5 \%$ Hemicell in a starter diet based on corn and soybeans and $1.0 \%$ guar gum showed an improvement in feed to weight gain ratio at all levels of enzyme supplementation (Daskiran et al., 2004; Hassan et al., 2012).

It is known that the $\beta$-mannanase enzyme affects carbohydrate metabolism. Thus, it has been experimentally shown that the intake of $\beta$-mannan by piglets decreased insulin secretion (Sambrook \& Rainbird, 1985), and reduced the absorption of glucose from feed (Rainbird et al., 1984). That is, the addition of Hemicell to the diet improved insulin secretion and glucose absorption due to $\beta$-mannan hydrolysis. The inclusion of the enzyme significantly increased the concentration of glucose in the blood plasma ( $(\mathrm{P}=0.064)$ but didn't affect the content of cholesterol, triglycerides, very low and low-density lipoproteins (Azarfar, 2013).

Our research has established that the use of an enzyme supplement $(0.025 \%)$ in the diet did not affect the macroscopic parameters of the cloacal bursa and spleen. According to Zou et al. (2006), the addition of $0.05 \%$ Hemicell to the diet increased the relative mass of immune organs (excluding the thymus of broilers in the third week, which were receiving $0.075 \%$ enzyme and the cloacal bag of broilers in the sixth week, which were receiving $0.025 \%$ of the enzyme). Also, this enzyme supplement $(0.05 \%)$ increased serum IgM concentration and T-lymphocyte prolifera- tion in 6-week-old broilers. The immunobiological reactivity of young poultry directly depends on the functioning of the immune system. It is known that the special feature of this broiler chickens' system in conditions of intensive feeding is that the organs are in the stage of development and formation, which causes a kind of reaction to antigenic irritation and stress factors of the external and internal environment of the macroorganism (El Sabry et al., 2016; Ifrah et al., 2017).

It is known that the cloacal bursa mass index on the 20th day of growing for unvaccinated poultry is 3.0 or more, and for a vaccinated bird, it should be at least 2.5 (Gromov, 2010). In our study, broiler chickens had high cloacal bursa mass index values at 15 days of age in both groups of chickens. With age, this indicator decreased, in the experimental group reaching a minimum parameter on the 25 th day, and in the control group it had decreased to a minimum by the 42 nd day. In the control group, the morphofunctional state of the cloacal bursa was found to be lower at all stages of rearing, in comparison with the experimental group and signs of immunosuppression were detected by the end of the growing period. This was manifested by a sharp decrease of the cloacal bursa absolute mass, the organ mass index, and the corresponding histological characteristics (a decrease in the nodules average length, a change in their shape, a thinned cortical layer, and delymphotisation). The morphofunctional state of the spleen of chickens from the control group remained high throughout the entire study period.

The significant effect of Hemicell on the broilers' immunity can be explained by the fact that the enzyme, entering the intestines, helps to reduce the content of $\beta$-mannan. As a result, $\beta$-mannan is broken down to mannan oligosaccharide (MOS), and absorbed by the body. Diets high in soy products, which contain a significant amount of anti-nutrients (Annison \& Choct, 1991), including $\beta$-mannan, are more likely to cause irritation of the intestinal mucosa, inflammation and degenerative processes. This, in turn, leads to an additional load on the immune system, causing first the activation of the central lymphoid organs' function, and then 
contributing to their premature involution (Ifrah et al., 2017). One of the possible reasons why $\beta$-mannanase may improve immunity is that $\beta$-mannan is degraded to mannan oligosaccharide (Wu et al., 2005). Mannan oligosaccharide can affect the immune system, observed by Shashidhara \& Devegowda, (2003), who reported that it can significantly increase maternal antibody levels in broilers. Mannan oligosaccharide can also improve intestinal absorption of certain nutrients such as $\mathrm{Zn}, \mathrm{Cu}$ and $\mathrm{Se}$, which in turn has a positive effect on the immune system (Saleh et al., 2018).

\section{Conclusion}

According to the research results, it was found that the use of the enzyme supplement $\beta$-mannanase (Hemicell) in the diet increased the productivity of broiler chickens, did not cause pronounced pathological changes, and affected the morphological and functional state of immune organs at the microscopic level. The production indices of the group of broiler chickens to whom an enzyme supplement was added to the diet, the number of birds at slaughter, survival rate, average weight of one bird at slaughter, average daily gain, meat yield in live weight were slightly higher than in the control group. At the same time, the total feed costs and the amount of feed per $1 \mathrm{~kg}$ of live weight were lower than for broiler chickens on a regular diet. The use of an enzyme supplement in the diet did not affect the macroscopic parameters of the cloacal bursa and spleen of the bird.

The active morphofunctional state of the cloacal bursa and spleen remained throughout the entire period of rearing birds of both groups, which was manifested by high indices of the absolute and relative mass of organs, a moderate level of development of tissue components and histological structures of the cloacal bursa (number, shape, size of lymphatic nodules, density of lymphocytes in cortex and medulla) and spleen (the number of lymphatic nodules and periarterioal lymphatic sheaths, their absolute sizes). Most of the morphometric parameters of the cloacal bursa and spleen, in particular the size of the nodules, the width of the cortex and the morphometric potential, were higher in the chickens from the experimental group. So, addition of $\beta$-mannanase (Hemicell) enzyme supplement to broiler chickens diet not only increases productivity, but also positively influences the morphofunctional state of the cloacal bursa.

\section{References}

Acamovic, T. (2001). Commercial application of enzyme technology for poultry production. World's Poultry Science Journal, 57(3), 225-242.

Annison, G., \& Choct, M. (1991). Anti-nutritive activities of cereal non-starch polysaccharides in broiler diets and strategies minimizing their effects. World's Poultry Science Journal, 47(3), 232-242.

Azarfar, A. (2013). Effect of hemicell enzyme on the performance, growth parameter, some blood factors and ileal digestibility of broiler chickens fed corn/ soybean-based diets. Journal of Cell and Animal Biology, 7(7), 85-91.

Bäck, R. (2009). Antigen-stimulated DNA synthesis in the bursa of fabricius of the chicken. Acta Pathologica Microbiologica Scandinavica Section A Pathology, 81(3), 337-343.

Classen, H. L., \& Bedford, M. R. (1991). The use of enzymes to improve the nutritive value of poultry feeds. Recent Advances in Animal Nutrition, 15(1), 95-116.

Daskiran, M., Teeter, R. G., Fodge, D., \& Hsiao, H. Y. (2004). An evaluation of endo- $\beta$-D-mannanase (Hemicell) effects on broiler performance and energy use in diets varying in $\beta$-mannan content. Poultry Science, 83(4), 662-668.

El Sabry, M. I., Yalçin, S., \& Turgay-İzzetoğlu, G. (2016). Effect of breeder age and lighting regimen on growth performance, organ weights, villus development, and bursa of fabricius histological structure in broiler chickens. Czech Journal of Animal Science, 60(3), 116-122.

Furuse, M., \& Mabayo, R. T. (1996). Effects of partially hydrolysed guar gum on feeding behaviour and crop emptying rate in chicks. British Poultry Science, 37(1), 223-227.

Genedy, H., Shousha, S., Azab, M., Ismail, R., \& Nafeaa, A. (2018). Effect of $\beta$ mannanase $\left(\right.$ Hemicell $\left.^{\mathbb{R}}\right)$ on growth performance and immunity of Japanese quail. Benha Veterinary Medical Journal, 34(2), 84-101.

Gromov, I. N. (2010). Morfologija immunnoj sistemy ptic pri vakcinacii protiv virusnyh boleznej [Morphology of the immune system of birds during vaccination against viral diseases]. VGAVM, Vitebsk (in Russian).

Hassan, S. M., Al-Yousef, Y. M., \& Bailey, C. A. (2012). Effects of guar bean, guar meal and guar gum on productive performance of broiler chicks. Asian Journal of Poultry Science, 7(1), 3440.
Ifrah, M. E., Perelman, B., Finger, A., \& Uni, Z. (2017). The role of the bursa of Fabricius in the immune response to vaccinal antigens and the development of immune tolerance in chicks (Gallus domesticus) vaccinated at a very young age. Poultry Science, 96(1), 51-57.

Jackson, M. E., Geronian, K., Knox, A., McNab, J., \& McCartney, E. (2004). A doseresponse study with the feed enzyme beta-mannanase in broilers provided with corn-soybean meal based diets in the absence of antibiotic growth promoters. Poultry Science, 83(12), 1992-1996.

Khomych, V. T., Kolych, N. V., Mazurkevych, T. A., Kostiuk, A. V., \& Hudz, N. V. (2015). Structural and functional features of the bursa of fabricius in domestic and wild birds. Scientific Messenger of LNU of Veterinary Medicine and Biotechnologies, Series Veterinary Sciences, 17(61), 181-186.

Krasnikov, G. A., \& Keleberda, N. I. (1999). O vozrastnyh osobennostjah fabricievoj sumki kur [On the age characteristics of the bursa of Fabricius of chickens]. Naukovyi Visnyk Natsionalnoho Ahrarnoho Universytetu, 16, 107-109 (in Rissian).

Kuzmenko, O., Bomko, V., Horchanok, A., Babenko, S., Tytariova, O., Slomchynskyi, M., Khalak, V., Polishchuk, S., Chemiavskyi, O., Prysiazhniuk, N., \& Lytvyshchenko, L. (2020). Effect of mannan oligosaccharides on productivity and quality of slaughter pig products. Ukrainian Journal of Ecology, 10(3), 181-186.

Lee, J. T., Connor-Appleton, S., Bailey, C. A., \& Cartwright, A. L. (2005). Effects of guar meal by-product with and without beta-mannanase Hemicell on broiler performance. Poultry Science, 84(8), 1261-1267.

López, S. (2008). Non-linear functions in animal nutrition. In: France, J., \& Kebreab, E. (Eds.). Mathematical modelling in animal nutrition. CAB eBooks International. Pp. 47-88.

Nabipour Afrouzi, H., Rezaei, M., \& Taghizadeh, V. (2016). Effect of guar meal and Hemicell enzyme on performance and carcass characteristics in broiler chicks. Animal Production Research, 4(4), 75-87.

Patel, M. B., \& McGinnis, J. (1985). The effect of autoclaving and enzyme supplementation of guar meal on the performance of chicks and laying hens. Poultry Science, 64(6), 1148-1156.

Plesovskih, N. J. (1999). Ispol'zovanie fermentnyh preparatov v pshenichno-jachmennyh kormosmesjah pri vyrashhivanii cypljat-brojlerov [The use of enzyme preparations in wheat-barley feed mixtures when growing broiler chickens]. Omsk (in Russian).

Rainbird, A. L., Low, A. G., \& Zebrowska, T. (1984). Effect of guar gum on glucose and water absorption from isolated loops of jejunum in conscious growing pigs. British Journal of Nutrition, 52(3), 489-498.

Ravindran, V., Selle, P., \& Bryden, W. (1999). Effects of phytase supplementation, individually and in combination, with glycanase, on the nutritive value of wheat and barley. Poultry Science, 78(11), 1588-1595.

Romanovych, M. M., Vishchur, O. I., Kurtyak, B. M., Matiukha, I. O., Mudrak, D. I., \& Romanovych, M. S. (2019). Influence of probiotics on histostructure of the bursa of Fabricius in broiler chickens. Journal for Veterinary Medicine, Biotechnology and Biosafety, 5(1), 5-9.

Rychen, G., Aquilina, G., Azimonti, G., Bampidis, V., Bastos, M. L., Bories, G., Chesson, A., Flachowsky, G., Gropp, J., Kolar, B., Kouba, M., López Alonso, M., López Puente, S., Mantovani, A., Mayo, B., Ramos, F., Saarela, M., Villa, R. E., Wallace, R. J., Wester, P., Brantom, P., Dierick, N. A., Glandorf, B., Herman, L., Kärenlampi, S., Aguilera, J., Anguita, M., \& Cocconcelli, P. S. (2017). Safety and efficacy of Hemicell ${ }^{\mathbb{R}}$ HT (endo-1,4- $\beta$-d-mannanase) as a feed additive for chickens for fattening, chickens reared for laying, turkey for fattening, turkeys reared for breeding, weaned piglets, pigs for fattening and minor poultry and porcine species. EFSA Journal, 15(1), e04677.

Saeed, M., Ayaşan, T., Alagawany, M., El-Hack, M., Abdel-Latif, M., \& Patra, A. (2019). The role of $\beta$-mannanase (Hemicell) in improving poultry productivity, health and environment. Brazilian Journal of Poultry Science, 21(3), 1-8.

Saleh, A. A., El-Far, A. H., Abdel-Latif, M. A., Emam, M. A., Ghanem, R., \& Abd El-Hamid, H. S. (2018). Exogenous dietary enzyme formulations improve growth performance of broiler chickens fed a low-energy diet targeting the intestinal nutrient transporter genes. PLoS One, 13(5), e0198085.

Sambrook, I. E., \& Rainbird, A. L. (1985). The effect of guar gum and level and source of dietary fat on glucose tolerance in growing pigs. British Journal of $\mathrm{Nu}-$ trition, 54(1), 27-35.

Shashidhara, R., \& Devegowda, G. (2003). Effect of dietary mannan oligosaccharide on broiler breeder production traits and immunity. Poultry Science, 82(8), 1319-1325.

Stehnii, A. B. (2013). Otsinka vplyvu inaktyvovanoi bivalentnoi vaktsyny proty vysokopatohennoho hrypu ptytsi ta Niukaslskoi khvoroby na imunokompetentni orhany silskohospodarskoi ptytsi [Evaluation of the effect of inactivated bivalent vaccine against highly pathogenic avian influenza and Newcastle disease on immunocompetent organs of poultry]. Veterynarna Medytsyna, 97, 286-288.

Tarek, K., Mohamed, M., Omar, B., \& Hassina, B. (2011). Morpho-histological study of the thymus of broiler chickens during post-hashing age. International Journal of Poultry Science, 11(1), 78-80. 
Wu, G., Bryant, M. M., Voitle, R. A., \& Roland, D. A. (2005). Effects of $\beta$-mannanase in corn-soy diets on commercial leghoms in second-cycle hens. Poultry Science, 84(6), 894-897.

Zangiabadi, H., \& Torki, M. (2010). The effect of a $\beta$-mannanase-based enzyme on growth performance and humoral immune response of broiler chickens fed diets containing graded levels of whole dates. Tropical Animal Health and Production, 42(6), 1209-1217.

Zharova, Y. Y. (2008). Age-related micromorphology of the large intestine of the chickens of the Iza Brown cross [Vozrastnaya makromikromorfologiya tolstogo kishechnika kur krossa "Iza Braun"]. The dissertation thesis for the scientific degree of the candidate of biological sciences. Ulyanovsk State University, Ulyanovsk (in Russian).

Zhyla, M., Shkil, M., \& Ponomarenko, S. (2016). Morphological description of internal organs of turkeys at application of preparation "Bioton". Scientific Messenger of LNU of Veterinary Medicine and Biotechnologies, Series Veterinary Sciences, 66, 74-78.

Zou, X. T., Qiao, X. J., \& Xu, Z. R. (2006). Effect of $\beta$-mannanase (Hemicell) on growth performance and immunity of broilers. Poultry Science, 85(12), 21762179. 